\title{
Indirect measures of human vagal withdrawal during head-up tilt with and without a respiratory acidosis
}

\author{
S. J. Brown - T. Mundel · M. Barnes • \\ J. A. Brown
}

Received: 7 May 2008/Accepted: 6 October 2008/Published online: 30 November 2008

(C) The Physiological Society of Japan and Springer 2008

\begin{abstract}
Human ECG records were analyzed during supine (SUP) rest and whole body $80^{\circ}$ head-up tilt (HUT), with a respiratory acidosis $\left(5 \% \mathrm{CO}_{2}\right)$ and breathing room air (RA). HUT increased heart rate in both conditions $\left(\mathrm{RA}_{\mathrm{SUP}}\right.$ $60 \pm 13$ vs. $\mathrm{RA}_{\mathrm{HUT}} 79 \pm 16 ; 5 \% \mathrm{CO}_{2 \text { SUP }} 63 \pm 12$ vs. $5 \% \mathrm{CO}_{2 \text { HUT }} 79 \pm 14$ beats $\mathrm{min}^{-1}$ ) and decreased mean $\mathrm{R}-\mathrm{R}$ interval, with no changes in the R-R interval standard deviation. When corrected for changes in frequency spectrum total power $(\mathrm{NU})$, the high frequency $(0.15-0.4 \mathrm{~Hz})$ component $\left(\mathrm{HF}_{\mathrm{NU}}\right)$ of heart rate variability decreased (RA $_{\text {SUP }} \quad 44.01 \pm 21.57$ vs. $\mathrm{RA}_{\text {HUT }} 24.05 \pm 13.09$; $5 \% \mathrm{CO}_{2 \text { SUP }} 69.23 \pm 15.37$ vs. $5 \% \mathrm{CO}_{2 \mathrm{HUT}} 47.64 \pm 21.11$ ) without accompanying changes in the low frequency $(0.04-0.15 \mathrm{~Hz})$ component $\left(\mathrm{LF}_{\mathrm{NU}}\right)\left(\mathrm{RA}_{\mathrm{SUP}} 52.36 \pm 21.93\right.$ vs. $\mathrm{RA}_{\text {HUT }} 66.58 \pm 19.49 ; 5 \% \mathrm{CO}_{2 \text { SUP }} 22.97 \pm 11.54$ vs. $5 \% \mathrm{CO}_{2 \mathrm{HUT}} 40.45 \pm 21.41$ ). Positive linear relations between the tilt-induced changes $(\Delta)$ in $\mathrm{HF}_{\mathrm{NU}}$ and $\mathrm{R}-\mathrm{R}$ interval were recorded for $\mathrm{RA}\left(\Delta \mathrm{HF}_{\mathrm{NU}}=0.0787(\Delta \mathrm{R}-\mathrm{R})\right.$ $\left.-11.3, R^{2}=0.79, P<0.05\right)$, and for $5 \% \mathrm{CO}_{2}\left(\Delta \mathrm{HF}_{\mathrm{NU}}=\right.$ $\left.0.0334(\Delta \mathrm{R}-\mathrm{R})+1.1, \quad R^{2}=0.82, \quad P<0.05\right) . \quad$ The decreased HF component suggested withdrawal of vagal activity during HUT. For both RA and $5 \% \mathrm{CO}_{2}$, the positive linear relations between $\Delta \mathrm{HF}_{\mathrm{NU}}$ and $\Delta \mathrm{R}-\mathrm{R}$ suggested that the greater the increase in heart rate with HUT, the greater the vagal withdrawal. However, a reduced range of $\Delta \mathrm{HF}$
\end{abstract}

S. J. Brown $(\bowtie) \cdot$ T. Mundel · M. Barnes

Institute of Food, Nutrition and Human Health,

Massey University, Private Bag 102-904,

Auckland, New Zealand

e-mail: s.j.brown@massey.ac.nz

\section{J. A. Brown}

Faculty of Medical and Health Sciences, University of Auckland,

Auckland, New Zealand during HUT with respiratory acidosis suggested vagal withdrawal was lower with a respiratory acidosis.

Keywords Autonomic nervous system .

Spectral analysis - Cardiovascular control · Hypercapnia

\section{Introduction}

Oscillations in the human heart rate at rest contribute to heart rate variability (HRV) [1-7], and may indicate cardiac sympatho-vagal balance [8]. Low (LF 0.04-0.15 Hz) and high (HF $0.15-0.4 \mathrm{~Hz}$ ) frequency bands form part of this variability and may be determined by spectral analysis of an $\mathrm{R}-\mathrm{R}$ interval tachogram. Reduced variability may suggest increased risk of mortality $[9,10]$, although regular physical exercise may increase HRV [10-12]. In humans, it is well established that moving from supine to an upright posture induces an increase in heart rate and a small decrease in end-tidal partial pressure of $\mathrm{CO}_{2}\left(\mathrm{PET}_{\mathrm{CO}_{2}}\right)$ [13-17]. Both postural change and hypercapnia are known to affect HRV, whereby the HF component has consistently been shown to decrease with head-up tilt (HUT) in normoxic healthy humans [14, 18-20]. However, directional changes in the LF component of HRV with tilting appear equivocal, with no change $[14,18,21]$ or an increase $[19$, 20, 22] being reported for healthy subjects. Hypercapnia has consistently been shown to increase HF cardiac variability [7, 23-25], suggestive of an increase in respiratory sinus arrhythmia $[24,26-28]$ but shown to have variable effects on LF variability [29].

It is unknown if the changes in heart rate induced by HUT are of similar magnitude irrespective of a respiratory acidosis. Also, increasing pulmonary ventilation by inhalation of a hypercapnic normoxic gas (which has been shown to 
increase HF power) may affect the magnitude of vagal withdrawal induced by HUT. Therefore, the aim of this study was to elevate the HF component of HRV by stimulating ventilation with inhalation of a hypercapnic normoxic gas. We aimed to compare the change in HF cardiac variability induced by HUT with the tilt-induced change in heart rate. It was hypothesized that the reduction in HF cardiac variability will be of similar magnitude in both conditions, despite being elevated by an increased ventilatory drive.

\section{Method}

With informed consent, 14 adult non-smokers [mean (SD) age 30 (7) years, range 20-42 years, nine males], with no known cardiovascular or respiratory abnormalities were studied at rest when supine (SUP) and during $80^{\circ}$ whole body head-up tilting (HUT). Subjects were at least $4 \mathrm{~h}$ post-prandial, and refrained from caffeine containing drinks in the preceding $4 \mathrm{~h}$. All procedures were approved by local Human Ethics Committee.

Subjects were randomized to a room air or hypercapnic normoxic condition in a cross-over design. There was no allocated washout period between study arms. Subjects were asked to breathe through a mouthpiece connected to a uni-directional low resistance demand valve connected to a 180 L Douglas bag filled with either room air (RA) or a gas mixture of $5 \% \mathrm{CO}_{2}, 21 \% \mathrm{O}_{2}, 74 \% \mathrm{~N}_{2}\left(5 \% \mathrm{CO}_{2}\right)$. The mouthpiece and valve added approximately $100 \mathrm{ml}$ ventilatory dead space to each subject.

An electrocardiogram (ECG limb lead 2, band-pass filtered between 10 and $200 \mathrm{~Hz}$, sampling frequency of $1 \mathrm{KHz}$ ) was recorded from each subject and collected using a multi-channel analogue-to-digital data acquisition system with appropriate software (PowerLab 4/25T and Chart v5.4, AD Instruments, Australia). Subjects were placed at a supine or $80^{\circ}$ position on the tilt table for $10 \mathrm{~min}$, and moving from each condition was achieved in approximately $3 \mathrm{~s}$. The ECG was recorded continuously throughout the procedure. The final $5 \mathrm{~min}$ period of SUP and HUT was used for HRV analysis.

ECG recordings were used to assess heart rate and HRV using commercially available software (HRV Module for Chart 5, AD Instruments, Australia). Heart rate was calculated by expressing R-R intervals as beats per minute (beats $\min ^{-1}$ ). Intervals between adjacent $\mathrm{R}$ waves were detected using a threshold detection of between 0.5 and $1.0 \mathrm{mV}$, and classified as artefact ( $<5 \mathrm{~ms}$ and $>2,000 \mathrm{~ms}$ ), ectopic (5-400 ms, and 1,400-2,000 ms), and normal (400-1,400 ms). The R-R period data were re-sampled to generate a waveform with uniform time interval. Data were analysed in the time domain using the mean $\mathrm{R}-\mathrm{R}$ interval, and the standard deviation of the normal mean $\mathrm{R}-\mathrm{R}$ interval, and in the frequency domain using a Fourier analysis and a Welch averaged periodogram method, and banded as very low frequency (VLF $0-0.04 \mathrm{~Hz}$ ), low frequency (LF 0.04-0.15 Hz), and high frequency (HF 0.15$0.4 \mathrm{~Hz}$ ). Total power for each spectrum was defined as the area under the spectrum from 0 to $0.5 \mathrm{~Hz}$, and normalised units (NU) for the LF and HF components (which take into account any changes in total spectrum power) were used to calculate the low frequency:high frequency ratio (LF:HF).

Group data were analysed using repeated measures analysis of variance (significance level at 0.05 ), with post hoc paired sample Student's $t$ tests used to determine where differences occurred (minimum level of significance adjusted using a Bonferroni correction such that $P<0.03$ ). Linear regression was used to model the relation between the changes $(\Delta)$ in HF power vs. the $\Delta$ in R-R interval induced by HUT. Values reported are mean (SD).

\section{Results}

Examples of an R-R interval tachogram (upper) and frequency spectrum (lower) are shown in Fig. 1 for both SUP (left) and HUT (right). In this subject (male 28 years) the mean heart rate was 53 beats min $^{-1}$ with HF and LF components of $56.8_{\mathrm{NU}}$ and $39.1_{\mathrm{NU}}$ respectively when supine. During HUT, the mean heart rate was 86 beats $\min ^{-1}$ with $\mathrm{HF}$ and LF components of $28.6_{\mathrm{NU}}$ and $63.4_{\mathrm{NU}}$ respectively.

Group mean (SD) data for heart rate variability in the time domain are reported in Table 1. A decrease in mean and median R-R interval was recorded for HUT, with no effect of $5 \% \mathrm{CO}_{2}$ on either. Heart rate increased with HUT with no effect of $5 \% \mathrm{CO}_{2}$. The square root of the mean squared differences in successive R-R intervals (RMSSD) was different between the RA and $5 \% \mathrm{CO}_{2}$ conditions during supine rest, and in both conditions, decreased with HUT.

Group mean (SD) data for heart rate variability in the frequency domain are reported in Table 2. No changes in total power were recorded when moving from SUP to HUT in either the RA or the $5 \% \mathrm{CO}_{2}$ condition. Compared to RA, the $5 \% \mathrm{CO}_{2}$ condition induced significant increases in $\mathrm{HF}_{\mathrm{LN}}$, and for both $\mathrm{LF}_{\mathrm{NU}}$ and $\mathrm{HF}_{\mathrm{NU}}$ values when both SUP and during HUT. HUT induced decreases in $\mathrm{HF}_{\mathrm{LN}}$ and $\mathrm{HF}_{\mathrm{NU}}$ during both RA and $5 \% \mathrm{CO}_{2}$ conditions. The LF:HF ratio was effected by both $5 \% \mathrm{CO}_{2}$ and by HUT, whereby it decreased in the $5 \% \mathrm{CO}_{2}$ condition compared to RA, and increased with HUT compared to SUP.

Significant linear relations were obtained for $\Delta \mathrm{HF}_{\mathrm{NU}}$ vs. $\Delta \mathrm{R}-\mathrm{R}$, as shown in Fig. 2, when breathing $\mathrm{RA}$ $\left(\Delta \mathrm{HF}_{\mathrm{NU}}=0.0787(\Delta \mathrm{R}-\mathrm{R})-11.3, R^{2}=0.79, P<0.05\right)$, and when breathing $5 \% \mathrm{CO}_{2}\left(\Delta \mathrm{HF}_{\mathrm{NU}}=0.0334(\Delta \mathrm{R}-\mathrm{R})\right.$ $\left.+1.1, R^{2}=0.82, P<0.05\right)$. The $\Delta \mathrm{R}-\mathrm{R}$ was also plotted against the $\Delta \mathrm{LF}_{\mathrm{NU}}: \mathrm{HF}_{\mathrm{NU}}$ ratio, as shown in Fig. 3. In both 
Fig. 1 Representative primary data recordings of heart rate variability in time (upper) and frequency (lower) domains during 5 min supine (left) and 5 min head-up tilt (right) epochs when breathing room air. The upper tachograms plot the $\mathrm{R}-\mathrm{R}$ interval for successive heart beats, and the frequency spectrum of this tachogram shown below is banded into very low frequency $(0$ $0.04 \mathrm{~Hz})$, low frequency $(0.04$ $0.15 \mathrm{~Hz}$ ), and high frequency $(0.15-0.4 \mathrm{~Hz})$. Data shown are from a male (28 years) and the mean heart rate was 53 beats $\min ^{-1}$ with $\mathrm{HF}$ and LF components of $56.8_{\mathrm{NU}}$ and $39.1_{\mathrm{NU}}$ respectively, when supine. During HUT, the mean heart rate was 86 beats $\min ^{-1}$ with $\mathrm{HF}$ and LF components of $28.6_{\mathrm{NU}}$ and $63.4_{\mathrm{NU}}$ respectively
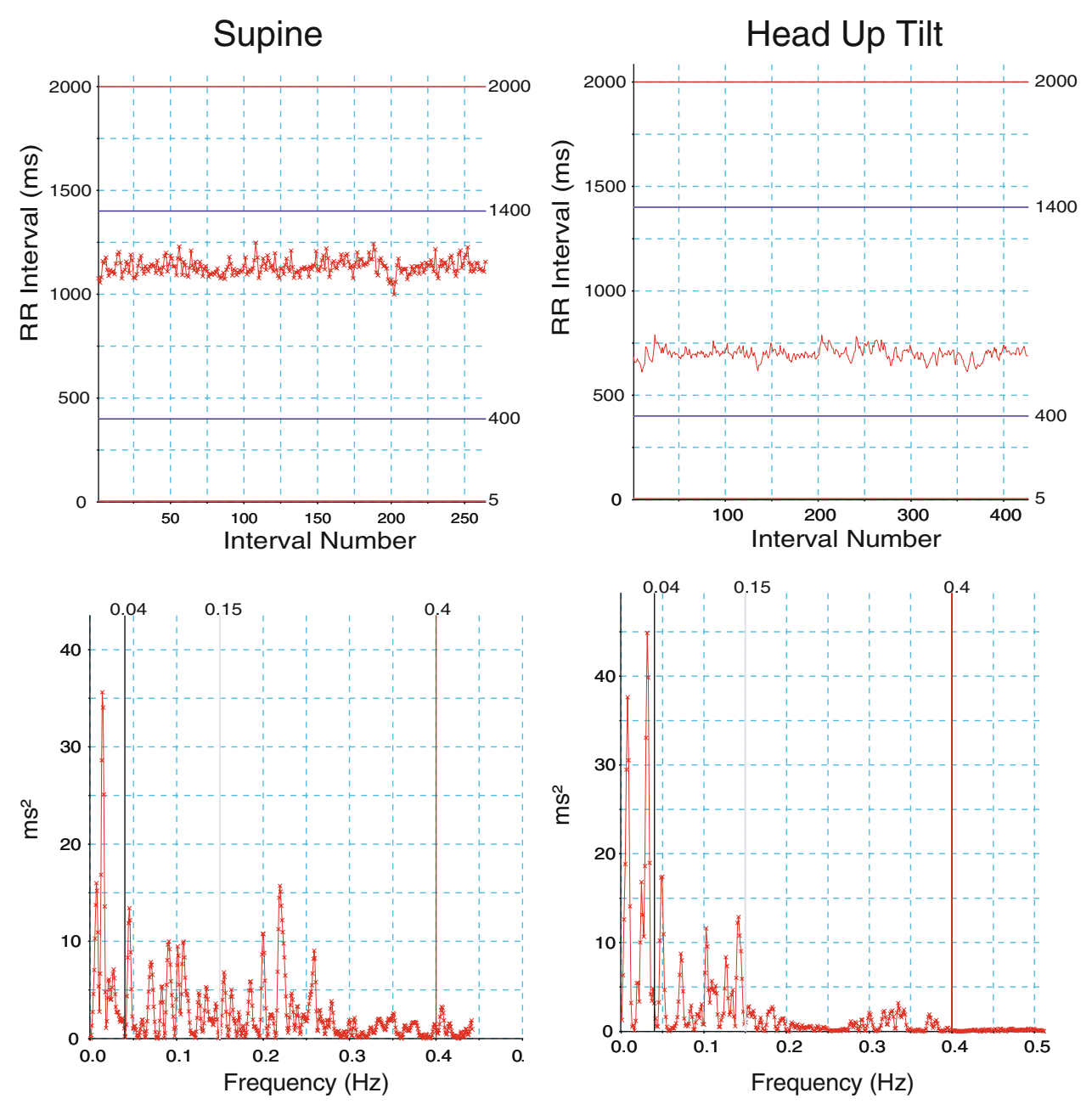

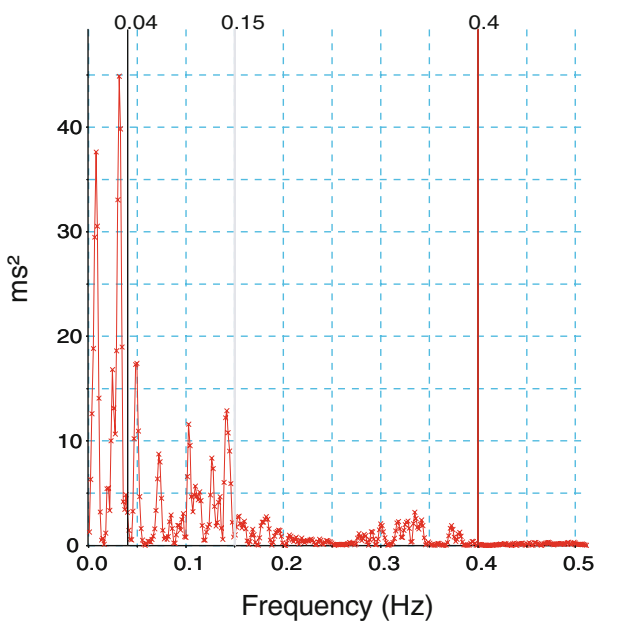

the RA and $5 \% \mathrm{CO}_{2}$ conditions, there was a general trend (regression lines shown in Fig. 3) of an increase in the difference in the ratio with a larger tilt-induced decrease in $\mathrm{R}-\mathrm{R}$ interval.

\section{Discussion}

This study compared vagal withdrawal—estimated by a reduced HF component of HRV in the frequency domain, and a reduced RMSSD in the time domain - when induced by HUT, with and without a respiratory acidosis. An elevated HF component was observed with a respiratory acidosis-this appeared to reduce the vagal withdrawal associated with HUT.

There is a possibility that the regression of a frequency domain measure with a time domain measure may contain some calculation artefact, such that a regular and periodic clustering of R-R intervals contributes to the oscillations observed in the tachogram. However, there is certainly no guarantee of a reciprocal change in $\mathrm{R}-\mathrm{R}$ interval and the HF component of HRV given that the frequency domain components of HRV provide a measure of the strength of oscillation, irrespective of whether the heart rate is high or low. For example, HF cardiac variability may be abolished with administration of atropine while mean heart rate remains unchanged [30]. Equally, HF cardiac variability will increase markedly with a respiratory acidosis with minimal [25] or no change [23] in R-R interval.

In the current study there was no evidence of tachycardia during hypercapnia when supine, consistent with a previous study [23]. However, others have reported small increases in heart rate with hypercapnia [24, 25, 31, 32]. A meta-analysis was conducted using the aforementioned five studies, in addition to the current study. There was no heterogeneity found between studies using $\chi^{2} \quad(n=61$, $\left.X^{2}=1.60, d f=5, P=0.06\right)$; thus data from the six studies were pooled for mean heart rates in normoxic and hypercapnic conditions for all 61 subjects. The standardised mean difference was 0.37 beats $\min ^{-1}(95 \% \mathrm{CI}-0.01$ to 0.75$)$. The meta-analysis found no overall effect of $\mathrm{CO}_{2}$ on heart rate $(z=1.90, P=0.06)$ for these studies.

In the current study, the high frequency component of HRV appeared to be sensitive to changes in pulmonary 
Table 1 Heart rate variability time domain measures when supine and during head-up tilt, with and without a respiratory acidosis induced by inhalation of $5 \% \mathrm{CO}_{2}$ in normoxic air

\begin{tabular}{|c|c|c|c|c|c|c|c|c|c|}
\hline \multicolumn{5}{|l|}{ Supine } & \multicolumn{5}{|l|}{ Head-up tilt } \\
\hline Mean (ms) & $\mathrm{SD} \mathrm{R}-\mathrm{R}(\mathrm{ms})$ & Median (ms) & RMSSD & $\begin{array}{l}\text { Heart rate } \\
\text { beats } \min ^{-1}\end{array}$ & Mean (ms) & SD R-R (ms) & Median (ms) & RMSSD & $\begin{array}{l}\text { Heart rate } \\
\text { beats } \min ^{-1}\end{array}$ \\
\hline \multicolumn{10}{|l|}{ Room air } \\
\hline $1,042(219)$ & 64 (19) & $1,044(221)$ & $71(37)$ & $60(13)$ & 794 (182) & $72(29)$ & 790 (186) & $56(32)$ & 79 (16) \\
\hline \multicolumn{10}{|l|}{$5 \% \mathrm{CO}_{2}$} \\
\hline 979 (202) & $98(40)$ & $1,036(216)$ & $112(61)$ & $63(12)$ & 788 (164) & 79 (44) & 776 (170) & $61(38)$ & 79 (14) \\
\hline
\end{tabular}

Reported values are mean (SD) for 14 subjects

Table 2 Heart rate variability frequency domain measures when supine and during head-up tilt, with and without a respiratory acidosis induced by inhalation of $5 \% \mathrm{CO}_{2}$ in normoxic air

\begin{tabular}{|c|c|c|c|c|c|c|c|c|c|c|c|c|c|}
\hline \multicolumn{7}{|l|}{ Supine } & \multicolumn{7}{|c|}{ Head-up tilt } \\
\hline $\mathrm{TP}_{\mathrm{LN}}$ & $\mathrm{VLF}_{\mathrm{LN}}$ & $\mathrm{LF}_{\mathrm{LN}}$ & $\mathrm{HF}_{\mathrm{LN}}$ & $\mathrm{LF}_{\mathrm{NU}}$ & $\mathrm{HF}_{\mathrm{NU}}$ & LF:HF & $\mathrm{TP}_{\mathrm{LN}}$ & $\mathrm{VLF}_{\mathrm{LN}}$ & $\mathrm{LF}_{\mathrm{LN}}$ & $\mathrm{HF}_{\mathrm{LN}}$ & $\mathrm{LF}_{\mathrm{NU}}$ & $\mathrm{HF}_{\mathrm{NU}}$ & LF:HF \\
\hline \multicolumn{14}{|c|}{ Room air } \\
\hline $\begin{array}{l}8.21 \\
(0.68)\end{array}$ & $\begin{array}{c}7.23 \\
(0.89)\end{array}$ & $\begin{array}{c}6.88 \\
(0.64)\end{array}$ & $\begin{array}{c}6.66 \\
(1.11)\end{array}$ & $\begin{array}{c}52.36 \\
(21.93)\end{array}$ & $\begin{array}{c}44.01 \\
(21.57)\end{array}$ & $\begin{array}{c}2.49 \\
(3.94)\end{array}$ & $\begin{array}{c}8.37 \\
(1.05)\end{array}$ & $\begin{array}{c}7.21 \\
(0.83)\end{array}$ & $\begin{array}{c}7.14 \\
(1.01)\end{array}$ & $\begin{array}{c}6.02^{\dagger} \\
(1.25)\end{array}$ & $\begin{array}{c}66.58 \\
(19.49)\end{array}$ & $\begin{array}{c}24.05^{\dagger} \\
(13.90)\end{array}$ & $\begin{array}{c}4.09 \\
(3.05)\end{array}$ \\
\hline \multicolumn{14}{|l|}{$5 \% \mathrm{CO}_{2}$} \\
\hline $\begin{array}{l}8.93 \\
(0.88)\end{array}$ & $\begin{array}{c}6.91 \\
(0.54)\end{array}$ & $\begin{array}{c}7.24 \\
(1.10)\end{array}$ & $\begin{array}{c}8.17 * \\
(1.17)\end{array}$ & $\begin{array}{c}22.97 * \\
(11.54)\end{array}$ & $\begin{array}{c}69.23 * \\
(15.37)\end{array}$ & $\begin{array}{c}0.38^{*} \\
(0.26)\end{array}$ & $\begin{array}{c}8.27 \\
(1.08)\end{array}$ & $\begin{array}{c}7.09 \\
(0.94)\end{array}$ & $\begin{array}{c}6.79 \\
(1.26)\end{array}$ & $\begin{array}{l}6.79 *^{\dagger} \\
(1.55)\end{array}$ & $\begin{array}{l}40.45^{* \dagger} \\
(21.41)\end{array}$ & $\begin{array}{l}47.64 *{ }^{\dagger} \\
(21.11)\end{array}$ & $\begin{array}{l}1.31{ }^{\dagger} \dagger \\
(1.43)\end{array}$ \\
\hline
\end{tabular}

Reported values are mean (SD) following transformation with natural logarithm function (LN), or normalised (NU) for total power (TP) of the spectrum between 0 and $0.5 \mathrm{~Hz}$

Very low frequency (VLF): 0-0.04 Hz, low frequency (LF): 0.04-0.15 Hz, high frequency (HF): $0.15-0.4 \mathrm{~Hz}$

$* P<0.03$ between room air and $5 \% \mathrm{CO}_{2}$

${ }^{\dagger} P<0.03$ between supine and head-up tilt

ventilation, as shown by others [23-27]. Also, in the current study, a decrease in HF cardiac variability was shown with HUT, again similar to the findings of others $[14,18-$ $20,33]$. However, in the present study, when using the HF component as an index of cardiac vagal tone, the expected vagal withdrawal during HUT was reduced when the HF component was already elevated by an increase in ventilation. This suggested that the HF component more closely reflected respiratory sinus arrhythmia when ventilation was elevated, and may be of limited use as an index of cardiac vagal tone at anything above resting ventilation. This is consistent with the widely reported vagal withdrawal (assessed by reduced HF cardiac variability) observed when ventilation has stabilised during the recovery from exercise [34, 35].

In the current study, there was no consistent directional change in the LF component of HRV with HUT during the room air condition, although $\mathrm{LF}_{\mathrm{NU}}$ increased with HUT during the acidosis condition. Pagani et al. [5] observed significant increases in cardiac variability at low frequencies with HUT, but also reported no correlation between the increases in the LF component and the tilt-induced increase in heart rate. Similarly, higher $\mathrm{LF}_{\mathrm{NU}}$ during HUT was recorded in trained and untrained subjects [33] but no correlation between time and frequency domain measures were reported. In the current study, the lack of a clear directional change in the LF component of HRV may reflect the small number of subject tested.

Cooke et al. [14] reported a decrease in $\mathrm{PET}_{\mathrm{CO}_{2}}$ from 5.1 to $3.9 \%$ with upright tilt while their subjects maintained a breathing frequency of $0.2 \mathrm{~Hz}$. Others [5] reported that during HUT, tidal volume was slightly lower when ventilation was controlled with a metronome $(0.33 \mathrm{~Hz})$, and this resulted in no accompanying changes in transcutaneous $\mathrm{P}_{\mathrm{CO}_{2}}$. An improvement in alveolar gas exchange efficiency may have contributed to the lowering of $\mathrm{PET}_{\mathrm{CO}_{2}}$ with $\mathrm{HUT}$ in the study by Cooke et al. [14], but this would suggest an increase in respiratory sinus arrhythmia [26, 36] and a concomitant increase in the HF component of HRV. However, Cooke et al. [14] reported a decrease in HRV at respiratory frequency with head-up tilt, consistent with the findings of the present study. It has been suggested that phasic cardiac vagal activity (defined by the magnitude of respiratory sinus arrhythmia) contributed to the efficiency 


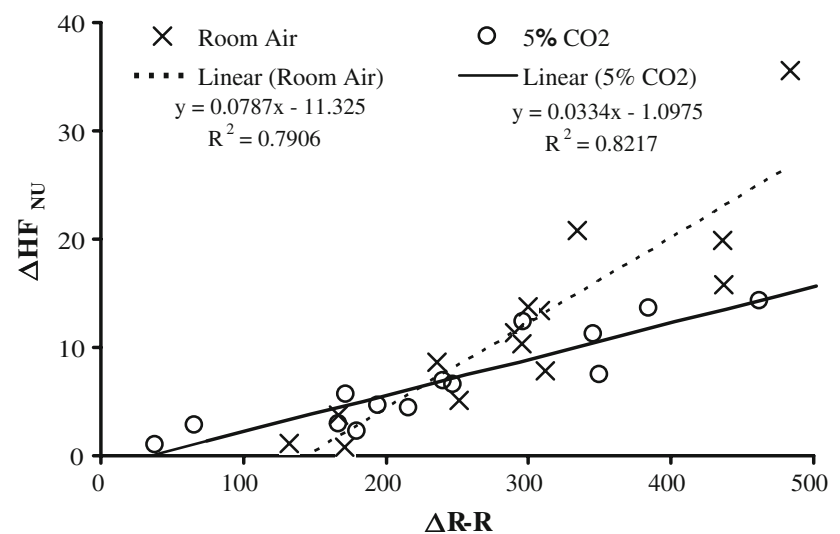

Fig. 2 Relation between the change $(\Delta)$ in the high frequency $\left(\mathrm{HF}_{\mathrm{NU}}\right)$ component of heart rate variability and the change $(\Delta)$ in $\mathrm{R}-\mathrm{R}$ interval when moving from supine to a head-up tilt, with (open circle, solid line) and without (crosses, dashed line) a respiratory acidosis induced by inhalation of $5 \% \mathrm{CO}_{2}$ in normoxic air. Linear regression equations with accompanying coefficients of determination are shown for both relations

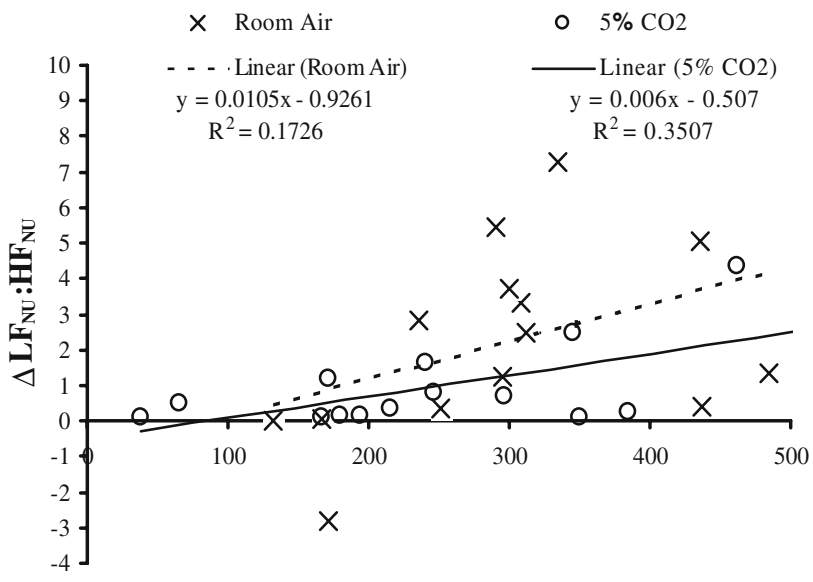

$\Delta \mathbf{R}-\mathbf{R}$

Fig. 3 Relation between the change $(\Delta)$ in the high frequency to low frequency ratio $\left(\mathrm{LF}_{\mathrm{NU}}: \mathrm{HF}_{\mathrm{NU}}\right)$ and the change $(\Delta)$ in $\mathrm{R}-\mathrm{R}$ interval when moving from supine to a head-up tilt, with (open circle, solid line) and without (crosses, dashed line) a respiratory acidosis induced by inhalation of $5 \% \mathrm{CO}_{2}$ in normoxic air. Linear regression equations with accompanying coefficients of determination are shown for both relations

of pulmonary gas exchange in humans, whereby the matching of pulmonary perfusion to ventilation decreases intrapulmonary shunt and alveolar dead space [30, 37, 38]. When atropine abolished the HF component of HRV in healthy, seated humans at rest [30], small but significant decreases in $\mathrm{Pa}_{\mathrm{O}_{2}}$ and arterial oxygen saturation were recorded. However, lowering $\mathrm{PET}_{\mathrm{CO}_{2}}$ with $\mathrm{HUT}$ may improve gas exchange efficiency independent of changes in respiratory sinus arrhythmia if the ventilation-perfusion matching is improved in an upright healthy lung [39]. In the present study, inhalation of the hypercapnic normoxic gas probably induced tracheobroncho-constriction [40] which potentially improved pulmonary gas exchange efficiency by reducing total dead space. Further studies are required to determine the influence of combined hypercapnia and HUT on $\mathrm{V}_{\mathrm{D}} / \mathrm{V}_{\mathrm{T}}$ and $\mathrm{V}_{\mathrm{E}} / \mathrm{V}_{\mathrm{CO}_{2}}$, particularly with reference to the non-invasive measures of cardiac autonomic control.

In conclusion, data in the current study do not support the original hypothesis. The vagal withdrawal induced by HUT, estimated using the HF component of HRV, was not of similar magnitude when subjects were acidotic. The influence of elevated ventilation on HRV components at respiratory frequency potentially masks the vagal withdrawal as changes in R-R interval with HUT appear independent of respiratory acidosis.

\section{References}

1. Akselrod S, Gordon D, Ubel FA, Shannon DC, Barger AC, Cohen RJ (1981) Power spectrum analysis of heart rate fluctuation: a quantitative probe of beat-to-beat cardiovascular control. Science 213:220-222

2. Aubert A, Seps B, Beckers F (2003) Heart rate variability in athletes. Sports Med 33:889-919

3. Grossman P, Taylor E (2007) Toward understanding respiratory sinus arrhythmia: relations to cardiac vagal tone, evolution and biobehavioral functions. Biol Psych 74:263-285

4. Malliani A, Pagani M, Lombardi F, Cerutti S (1991) Cardiovascular neural regulation explored in the frequency domain. Circulation 84:482-492

5. Pagani M, Lombardi F, Guzzetti S, Rimoldi O, Furlan R, Pizzinelli P, Sandrone G, Malfatto S, Dell'Orto S, Piccaluga E (1986) Power spectral analysis of heart rate and arterial pressure variabilities as a marker of sympatho-vagal interaction in man and conscious dog. Circ Res 59:178-193

6. Perini R, Veicsteinas A (2003) Heart rate variability and autonomic activity at rest and during exercise in various physiological conditions. Eur J Appl Physiol 90:317-325

7. Poyhonen M, Syvaoja S, Hartikainen J, Ruokonen E, Takala J (2004) The effect of carbon dioxide, respiratory rate and tidal volume on human heart rate variability. Acta Anaesth Scand 48:93-101

8. Eckberg DL (1983) Human sinus arrhythmia as an index of vagal cardiac outflow. J Appl Physiol 54:961-966

9. Huikuri H, Makikallio T, Airaksinen J, Mitrani R, Castellanos A, Myerburg R (1999) Measurement of heart rate variability: a clinical tool or a research toy? J Am Col Cardiol 34:1878-1883

10. Tsuji H, Venditti F, Manders E, Evans J, Larson M, Feldman C, Levy D (1994) Reduced heart rate variability and mortality risk in an elderly cohort. The Framinghan Heart Study. Circulation 90:878-883

11. Levy W, Cerqueira M, Harp G, Johannessen K, Abrass I, Schwartz R, Stratton J (1998) Effect of endurance exercise training on heart rate variability at rest in healthy young and older men. Am J Cardiol 82:1236-1241

12. Sandercock GRH, Grocott-Mason R, Brodie DA (2007) Changes in short-term measures of heart rate variability after eight weeks of cardiac rehabilitation. Clin Auton Res 17:39-45 
13. Anthonisen NR, Bartlett D, Tenney SM (1965) Postural effect on ventilatory control. J Appl Physiol 20:191-196

14. Cooke WH, Hoag JB, Crossman AA, Kuusela TA, Tahvanainen KUO, Eckberg DL (1999) Human responses to upright tilt: a window on central autonomic integration. J Physiol 517:617-628

15. Gisolf J, Wilders R, Immink RV, van Lieshout JJ, Karemaker JM (2004) Tidal volume, cardiac output and functional residual capacity determine end-tidal $\mathrm{CO}_{2}$ transient during standing up in humans. J Physiol 554:579-590

16. LeLorier P, Klein GJ, Krahn A, Yee R, Skanes A, Shoemaker JK (2003) Combined head-up tilt and lower body negative pressure as an experimental model of orthostatic syncope. J Cardiovasc Electophysiol 14:920-924

17. Stewart JM, Medow MS, Cherniack NS, Natelson BH (2006) Postural hypocapnic hyperventilation is associated with enhanced peripheral vasoconstriction in postural tachycardia syndrome with normal supine blood flow. Am J Physiol Heart Circ Physiol 291:904-913

18. Kamiya A, Hayano J, Kawada T, Michikami D, Yamamoto K, Ariumi H, Shimizu S, Uemura K, Miyamoto T, Aiba T, Sunagawa K, Sugimachi M (2005) Low-frequency oscillation of sympathetic nerve activity decreases during development of tiltinduced syncope preceding sympathetic withdrawal and bradycardia. Am J Physiol Heart Circ Physiol 289:H1758-H1769

19. Kochiadakis GE, Kanoupakis EM, Igoumenidis NE, Marketou ME, Solomou MC, Vardas PE (1998) Spectral analysis of heart rate variability during tilt-table testing in patients with vasovagal syncope. Int J Cardiol 64:185-194

20. Piccirillo G, Fimognari F, Viola E, Marigliano V (1995) Ageadjusted normal confidence intervals for heart rate variability in healthy subjects during head-up tilt. Int J Cardiol 50:117-124

21. Mukai S, Hayano J (1995) Heart rate and blood pressure variabilities during graded head-up tilt. J Appl Physiol 78:212-216

22. Sanderson JE, Yeung LY, Yeung DT, Kay RL, Tomlinson B, Critchley JA, Woo KS, Bernardi L (1996) Impact of changes in respiratory frequency and posture on power spectral analysis of heart rate and systolic blood pressure variability in normal subjects and patients with heart failure. Clin Sci (Lond) 91:35-43

23. Brown SJ, Munel T, Brown JA (2007) Cardiac vagal control and respiratory sinus arrhythmia during hypercapnia in humans. J Physiol Sci 57:337-342

24. Sasano N, Vesely A, Hayano J, Sasano H, Somogyi R, Preiss D, Miyasaka K, Katsuya H, Iscoe S, Fisher J (2002) Direct effect of $\mathrm{Pa}_{\mathrm{CO} 2}$ on respiratory sinus arrhythmia in conscious humans. Am J Physiol Heart Circ Physiol 282:H973-H976

25. Tzeng YC, Larsen PD, Galletly DC (2007) Effects of hypercapnia and hypoxemia on respiratory sinus arrhythmia in conscious humans during spontaneous respiration. Am J Physiol Heart Circ Physiol 292:H2397-H2407

26. Giardino N, Glenny RW, Borson S, Chan L (2003) Respiratory sinus arrhythmia is associated with efficiency of pulmonary gas exchange in healthy humans. Am J Physiol Heart Circ Physiol 284:H1585-H1591

27. Toska K, Eriksen M (1993) Respiration-synchronous fluctuations in stroke volume, heart rate and arterial pressure in humans. J Physiol 472:501-512

28. Yasuma F, Hirai M, Hayano J (2001) Differential effects of hypoxia and hypercapnia on respiratory sinus arrhythmia in conscious dogs. Jpn Circ J 65:738-742

29. Sato F, Nishimura M, Igarashi T, Yamamoto M, Miyamoto K, Kawakami Y (1996) Effects of exercise and $\mathrm{CO}_{2}$ inhalation on intersubject variability in ventilatory and heart rate responses to progressive hypoxia. Eur Respir J 9:960-967

30. Ito S, Sasano H, Sasano N, Hayano J, Fisher JA, Katsuya H (2006) Vagal nerve activity contributes to improve the efficiency of pulmonary gas exchange in hypoxic humans. Exp Physiol 91:935-941

31. Brown SJ, Howden R (2007) The effects of respiratory acidosis on human heart rate variability. Adv Exp Med Biol 605:361-365

32. Howden R, Lightfoot T, Brown SJ, Swaine I (2004) The effects of breathing $5 \% \mathrm{CO}_{2}$ on human cardiovascular responses and tolerance to orthostatic stress. Exp Physiol 89:465-471

33. Martinelli FS, Chacon-Mikahil MPT, Martins LEB, Lima-Filho EC, Golfetti R, Paschoal MA, Gallo-Junior L (2005) Heart rate variability in athletes and non-athletes at rest and during head-up tilt. Braz J Med Biol Res 38:639-647

34. Arai Y, Saul JP, Albrecht P, Hartley LH, Lilly LS, Cohen RJ, Colucci WS (1989) Modulation of cardiac autonomic activity during and immediately after exercise. Am J Physiol 256:H132H141

35. Takahashi T, Okada A, Saitoh T, Hayano J, Miyamoto Y (2000) Difference in human cardiovascular response between upright and supine recovery from upright cycle exercise. Eur J Appl Physiol 81:233-239

36. Hayano J, Yasuma F (2003) Hypothesis: respiratory sinus arrhythmia is an intrinsic resting function of cardiopulmonary system. Cardiovasc Res 58:1-9

37. Hayano J, Yasuma F, Okada A, Mukai S, Fujinami T (1996) Respiratory sinus arrhythmia-phenomenon improving pulmonary gas exchange and circulatory efficiency. Circulation 94:842-847

38. Yasuma F, Hayano J (2004) Respiratory sinus arrhythmia-why does the heart beat synchronize with respiratory rhythm? Chest 125:683-690

39. West J (1985) Physiological basis of medical practice, 11th edn. Williams \& Wilkins, London, pp 546-585

40. Dickstein J, Greenberg A, Kruger J, Robicsek A, Silverman JA, Sommer LZ, Sommer DD, Volgyesi GA, Iscoe S, Fisher JA (1996) $\mathrm{P}_{\mathrm{CO} 2}$ affects tracheal tone during apnea in anesthetized dogs. J Appl Physiol 81:1184-1189 